\title{
Reputation Management in Times of the Pandemic - Empirical Analysis of Selected Health Care Providers Operating in the Slovak Market
}

\author{
Frantisek Pollak ${ }^{1, *}$, Peter Markovic ${ }^{1}$, Bozka Malinak ${ }^{2}$, Katarina Belovodska ${ }^{2}$ \\ ${ }^{1}$ University of Economics in Bratislava, Faculty of Business Management, Department of Business Finance, Dolnozemská cesta 1/b, \\ 852 35, Bratislava, Slovakia \\ ${ }^{2}$ Acuity Engineering \& Consulting Service Ltd, 10327122 St NW, T5N1M1 Edmonton AB, Canada
}

\begin{abstract}
The issue of corporate reputation management is one of the key areas in the process of building trust between the supply and demand side of the market. The services sector, which, as a rule, works predominantly with intangible products, is particularly vulnerable to reputational damage. The presented study aims to examine the impact of the COVID-19 pandemic on the overall level of reputation of eleven Slovak teaching hospitals. The data sources used in the form of publicly available databases cover both the traditional factors of the brick-and-mortar market, as well as the factors related to the virtual Internet environment. The results of the analysis point to the fact that while the traditional level of reputation of the entities reflected changes in the market only to a relatively limited extent, the level of the online reputation of the analysed entities decreased significantly due to the pandemic. This finding underscores the fact about the fragility of reputation in the Internet environment. By comparing individual reputational factors in the pre-pandemic period with the situation during the peak of the third wave of the pandemic, the study offers a relatively compact knowledge base for formulating basic transformations for comprehensive research into the impact of a pandemic on corporate competitiveness.
\end{abstract}

Keywords: corporate reputation; reputation management; pandemic; COVID-19; teaching hospital

\section{Introduction}

Corporate reputation management is an important part of the overall management of corporate assets. Research [1-3] points to the fact that the issue of reputation is a crucial factor in the process of building trust between the organization and its customer. It does not have to be just a purely market environment. We also encounter the application of reputation management in corporate management in areas such as education or healthcare [4-5]. In the present study, we focused on the field of health care, or rather the area of health care providers. The study builds on the relatively extensive knowledge base of the authors [6-8], in which the issue of reputation management of entities operating (not only) in the health care sector during the period preceding the outbreak of the COVID-19 pandemic was thoroughly developed. However, the sharp onset of a pandemic in the first half of 2020 largely affected almost all areas of the market [9-11], and healthcare was no exception. On the contrary, the health care sector has come to the fore. The spring of 2020 was marked by a high degree of admiration and respect for healthcare professionals and the entire healthcare sector. With the aftermath of the pandemic, the initial enthusiasm of the demand side of the market gradually began to subside. The transition from the acute to the chronic part of the pandemic brought with it a relatively critical response from a large part of the market. This was based on both the overall congestion of the system and the relatively polarized market sentiment [12]. All these factors, whether it is the weak predictability of the situation at the beginning of the pandemic, or the significant rate of burnout resulting from the depletion of available resources (it should be noted here that it is both financial/material and human), have only exacerbated the overall fragility of the reputation. It is the fragility that is, according to the literature, the most characteristic feature of reputation [13-14]. The aim of the presented study is therefore to examine the effects of a pandemic on the reputation of healthcare providers. For the highest degree of authenticity and informative value of the knowledge produced, we chose eleven teaching hospitals that operate on the Slovak market of health care providers as a research sample. As this is a complex issue, we will examine both traditional and modern aspects of corporate reputation over time. The reference pre-pandemic basis for the analysis will be data from 2018. Traditional aspects of corporate reputation will be represented by assessments of entities by the state health insurance company based on the Patient Satisfaction Survey 2018 [15] and the Patient Satisfaction Survey 2020 [16]. Modern aspects will be represented by individual reputators synthesized within the parameter Total Online Reputation "TOR" measured in 2018 [17], which we will follow up with the current dataset prepared for the needs of the presented study.

\footnotetext{
* Corresponding author: frantisek.pollak@euba.sk
} 
Given the research goal as well as the nature of the available data, it is therefore possible to formulate the following research question:

- Is it possible to identify significant changes in the reputation of entities in the pre-COVID-19 and COVID-19 periods?

The main research question can then be divided into two sub-questions based on the environment, namely:

- Have there been changes in the traditional reputation of subjects as expressed in patient satisfaction surveys?

- Have there been changes in the online reputation of entities?

From the point of view of the composition of the content of the presented study, we have chosen the traditional structure, where we will begin with a brief overview of the current state in the researched issues from the point of view of key concepts of the topic. Subsequently, we will move smoothly to the description of the objectives and methodological apparatus that is used in the study. Findings will be interpreted through summary tables; key facts will be visualized. The conclusion will summarize all the key findings and describe the main limitations and perspectives of the research. The present study is prepared with the aim of expanding the knowledge base for subsequent comprehensive research of the effects of a pandemic on corporate competitiveness.

\subsection{Traditional reputation factors}

We encounter reputation as a concept of the traditional world of bricks and mortar in the cross-sectional literature in various areas of science. The economic sciences view reputation as one of the components of a company's portfolio of intangible assets [18-19]. Management sciences, in turn, view the issue of reputation as a concept based on the tradition of protecting goodwill. In marketing, in turn, reputation is often confused with the image of the organization, even though reputation greatly exceeds the scope of image issues. Despite the apparent ambiguity in terminology, all concepts come together in a confidence-building process. Confidence integrates all the mentioned concepts in terms of content and scope, and from the point of view of science, it raises the issue to the extent of the philosophical concept [20]. When it comes to the issue of trust or even faith, we go thematically thousands of years into the history of the work of ancient philosophers. Given this fact, it can be stated that the factors influencing the issue in the traditional world are well known to all market participants. Unless the entity has direct knowledge of the active management of its reputation, it has the well-known know-how needed to ensure that it does not damage its reputation. Also, from the point of view of the media as a carrier of information, the reputation in its traditional understanding is relatively well controllable. Reputation management in its understanding as it was known from the end of the twentieth century is dominantly determined by so-called "hard" factors, such as the economic results of the organization, the rate, and extent of innovation, consistency in values, and attitudes, etc. We could include all these factors as "objective quality factors". In contrast, from the point of view of the digital environment, the issue of reputation is much more diverse.

\subsection{Reputation factors in the online environment of the Internet}

When it comes to the digital environment of the Internet, reputation dynamically multiplies the number of quantifiable as well as non-quantifiable variables needed for its qualified management. The Internet as a medium is usually unregulated in nature [21-22], the authenticity of messages distributed by the network is questionable. Whereas in the past it was necessary to control "only" the main information flows in the form of publicity in opinion-forming media for reputation management, today such an approach is insufficient. Social media has introduced the concept of open communities, which allow both sides of the market to interact in real-time [23]. In any case, a targeted approach creates considerable information asymmetry with enormous pressure on corporate resources. Control of these processes is also quite difficult. The number of variables is dynamic, new media are coming to the market, which is constantly creating demand for expanding the digital information portfolio of companies. If we consider that the unregulated nature of the Internet shortens communication channels and, on the other hand, constantly generates new communication platforms, we get into an unenviable situation as managers. That is why it is important to constantly generate new knowledge and continuously explore this dynamic issue. Organizations of all sizes must accept the same rules of the game [24-25] if they want to succeed in hectic and turbulent hypermedia times. However, as researchers, we must select a quantifiable number of variables, as it is not possible to perform an empirical analysis with non-quantifiable variables. For the purposes of this analysis, the number of quantifiable variables has been reduced to dominant media in the form of major industry players such as Google and Facebook. Authenticity and objectivity are, in our view, the key to online reputation management. From the point of view of factors that influence the reputation of subjects in the online environment, it can be stated that they take the form of a synthesis of factors of objective and subjective perceived quality.

\section{Methodology}

The presented study aims to examine the effects of a pandemic on the reputation of health care providers. Given the research goal as well as the nature of the available data, the following research question is formulated: 
- Is it possible to identify significant changes in the reputation of entities in the pre-COVID-19 and COVID-19 periods?

The main research question can then be divided into two sub-questions based on the environment, namely:

- Have there been changes in the traditional reputation of subjects as expressed in patient satisfaction surveys?

- Have there been changes in the online reputation of entities?

For the highest degree of authenticity and informative value of the knowledge produced, we have chosen as a research set the entire segment of health care providers, these are entities that provide their services in the Slovak Republic. As a research sample, we selected eleven teaching hospitals, which represent key representatives of the industry in the research. As this is a complex issue, we will examine both traditional and modern aspects of corporate reputation in the run-up to and during the COVID-19 pandemic.

The traditional aspects of corporate reputation will be represented by a ranking of entities based on the Patient Satisfaction Survey 2018 [15] and 2020 [16] conducted annually by the state health insurance company, hereinafter referred to as "VšZP".

Based on the created knowledge base [6-8], modern aspects will be represented by a synthesis of individual partial online reputators within the parameter Total Online Reputation "TOR" measured in 2018 [26], which we will follow in the study by compiling an up-to-date overview. The indicator "TOR" represents a complex quantity calculated for each analyzed subject individually based on the following formula (1):

$$
T O R=\frac{R_{A S A}+\sum_{i=1}^{n} R_{i}}{n+1}
$$

Where:

TOR- Total online reputation $v \%$

$\mathrm{R}_{i^{-}} \quad$ Reputation determinant (\% score according to the i- reputation determinant)

$\mathrm{R}_{A S A^{-}} \quad$ ASA reputation determinant (\% score according to the advanced sentiment analysis)

n- $\quad$ Number of determinants

From the point of view of the determinants that enter as $\mathrm{R}_{i}$ into the calculation, we take into account the following:

- Facebook rating;

- Google rating;

- $\quad$ Azet.sk rating.

From $\mathrm{R}_{A S A}$ 's point of view, we use for this case a two-stage sentiment analysis [7] of the first ten search results based on the official designation/name of the entity via Google search engine, where general Google search results are supplemented by search results in the "news" category.

The basic scientific methods used in the study are analysis and synthesis, we also work with elements of abstraction.

The data are processed via the Excel spreadsheet program of the MS Office 365 office suite.

For the purposes of data presentation, we use overview tables, which are graphically interpreted in specific cases.

\section{Results and Discussion}

Managing corporate reputation is a relatively complicated process, especially when unexpected variables enter the process. In the case of our research, such a variable was the COVID-19 pandemic, which created significantly specific conditions in the market of healthcare providers. In this chapter, we will gradually present the partial outputs of the analysis to answer the primary research question. Attention will be paid to both the traditional and digital markets.

\subsection{The period before the outbreak of the COVID-19 pandemic}

The year 2018 was chosen as the reference period for comparison, which represented a relatively stable reference point in the selected market. Based on data from the study [26] and interpretation in the study [17], it is possible to present in Table 1. complex state values of the monitored variables measured in the pre-pandemic period as follows: 
Table 1. Offline and Online Reputation in 2018

\begin{tabular}{|l|c|c|}
\hline \multicolumn{1}{|c|}{ Subject } & VšZP ranking & TOR score (\%) \\
\hline University Hospital Martin & 1. & 83 \\
\hline Central Military Hospital SNP Ruzomberok & 2. & 80 \\
\hline Faculty Hospital F. D. Roosevelt Banska Bystrica & 3. & 72 \\
\hline Faculty Hospital Nove Zamky & 4. & 70 \\
\hline Faculty Hospital Nitra & 5. & 51 \\
\hline Faculty Hospital J.A.Reiman Presov & 6. & 62 \\
\hline University Hospital of L. Pasteur Kosice & 7. & 70 \\
\hline Faculty Hospital Zilina & 8. & 51 \\
\hline University Hospital Bratislava & 9. & 67 \\
\hline Faculty Hospital Trnava & 10. & 63 \\
\hline Faculty Hospital Trencin & 11. & 70 \\
\hline
\end{tabular}

Source: Autor based on [15,26].

From the point of view of patient evaluation based on a survey conducted by the state health insurance company, it can be stated that nine out of eleven providers achieved a rating of "average", only two subjects, namely University Hospitals in Trnava and Trenčín in patient evaluation achieved a rating of "worst ". At the same time, none of the subjects in the sample achieved a "best" rating. Regarding the TOR, i.e., the overall level of the entity's online reputation, the situation is much more diverse. The first two subjects in the VšZP rank also occupy the first places in comparison based on online reputation, even in the same order. At the same time, the University Hospital in Martin achieved the highest coefficient based on the sum of the sentiment scores of the first ten Google search results, which is one of the partial parameters of the TOR score. The Central Military Hospital in Ružomberok has reached the level of $100 \%$ in terms of user ratings on the social network Facebook. Given the general findings, it should be noted that all subjects in the analysis of the pre-COVID-19 period reached at least $50 \%$ of their online potential.

\subsection{Period during the COVID-19 pandemic}

Based on the same methodology, we developed the following overview Table 2, through which it is possible to monitor the development of the monitored values of the analyzed subjects in the period during the COVID-19 pandemic.

Table 2. Offline and Online Reputation in 2021

\begin{tabular}{|l|c|c|}
\hline \multicolumn{1}{|c|}{ Subject } & VšZP ranking & TOR score (\%) \\
\hline Central Military Hospital SNP Ruzomberok & 1. & 71 \\
\hline University Hospital Martin & 2. & 80 \\
\hline Faculty Hospital F. D. Roosevelt Banska Bystrica & 3. & 66 \\
\hline Faculty Hospital Nove Zamky & 4. & 58 \\
\hline Faculty Hospital Zilina & 5. & 44 \\
\hline Faculty Hospital J. A. Reiman Presov & 6. & 32 \\
\hline Faculty Hospital Nitra & 7. & 41 \\
\hline Faculty Hospital Trnava & 8. & 59 \\
\hline Faculty Hospital Trencin & 9. & 61 \\
\hline University Hospital of L. Pasteur Kosice & 10. & 33 \\
\hline University Hospital Bratislava & 11. & 48 \\
\hline
\end{tabular}

Source: Autor based on [16].

From the point of view of patient evaluation based on a survey carried out by the state health insurance company, it is possible to record an exchange between the first and second place for the first three providers. The best players on the market maintain their position in the long run. It is also possible to record the decline of two large market players, namely university hospitals in Prešov and Košice to the last ranks. A positive finding from the point of view of traditional 
reputation is the fact that none of the evaluated subjects achieves the rating "worst", while all subjects are evaluated by patients as "average" according to the methodology used. From the point of view of online reputation, the assumption of its fragility is confirmed. Subjects underwent a stress test during the pandemic, which was reflected in the sum of the results of the measured sentiments in the first ten Google search results. The difficult period of the fight against the pandemic also resulted in a decrease in customer ratings of official profiles of entities on the social network Facebook and Google ratings of profiles directly in the search results according to the official name of the entity. Only the University Hospital in Martin achieved the first quartile of evaluation according to the overall level of online reputation, while up to five out of a total of eleven subjects fell below the $50 \%$ level. In terms of possible causes of the decline in overall reputation, the analysis revealed both objective factors in the form of negative publicity related to the difficult pandemic situation, as well as possible managerial failures within individual levels of management of selected entities/health care sector in turbulent conditions of a graduating pandemic. Until the main research question can be answered, it is necessary to visualize and discuss in more detail the differences in the observed periods.

\subsection{Comparison of pre-pandemic and pandemic period}

By processing the empirical material produced in the analysis process, it was possible to obtain a more detailed overview of the impact of the COVID-19 pandemic on the reputation management of entities operating in the healthcare sector. In general, it is argued that online reputation is more prone to damage, as it is affected by factors that do not generally constitute the primary area of concern for the management of an entity. Also, the dominantly intangible nature of the factors influencing online reputations is largely more sophisticated. This creates additional requirements for resource allocation. The limited nature of resources and the unlimited nature of external factors were also reflected in the results of our research in terms of comparing pre-pandemic and pandemic indicators. The following Table 3 shows the shifts in the rankings of entities within the traditional and digital world as follows:

Table 3. Offline and Online Reputation- 2018 vs. 2021

\begin{tabular}{|c|c|c|c|}
\hline Subject & $\begin{array}{r}\mathbf{V s ̌ Z} \\
20\end{array}$ & $\begin{array}{l}\text { king } \\
21\end{array}$ & $\begin{array}{c}\text { TOR score }(\%) \\
2018 / 2021\end{array}$ \\
\hline University Hospital Martin & $1 . / 2$ & $(\downarrow 1)$ & $83 / 80(\downarrow 3 \%)$ \\
\hline Central Military Hospital SNP Ruzomberok & $2 . / 1$ & $(\uparrow 1)$ & $80 / 71(\downarrow 9 \%)$ \\
\hline Faculty Hospital F. D. Roosevelt Banska Bystrica & $3 . / 3$. & $(=)$ & $72 / 66(\downarrow 6 \%)$ \\
\hline Faculty Hospital Nove Zamky & $4 . / 4$. & $(=)$ & $70 / 58(\downarrow 12 \%)$ \\
\hline Faculty Hospital Nitra & $5 . / 7$. & $(\downarrow 2)$ & $51 / 41(\downarrow 10 \%)$ \\
\hline Faculty Hospital J.A.Reiman Presov & $6 . / 6$ & $(=)$ & $62 / 32(\downarrow 30 \%)$ \\
\hline University Hospital of L. Pasteur Kosice & $7 . / 10$. & $(\downarrow 3)$ & $70 / 33(\downarrow 27 \%)$ \\
\hline Faculty Hospital Zilina & $8 . / 5$ & $(\uparrow 3)$ & $51 / 44(\downarrow 7 \%)$ \\
\hline University Hospital Bratislava & $9 . / 11$. & $(\downarrow 2)$ & $67 / 48(\downarrow 19 \%)$ \\
\hline Faculty Hospital Trnava & $10 . / 8$. & $(\uparrow 2)$ & $63 / 59(\downarrow 4 \%)$ \\
\hline Faculty Hospital Trencin & 11./9. & $(\uparrow 2)$ & $70 / 61(\downarrow 9 \%)$ \\
\hline
\end{tabular}

Source: Author.

From the point of view of comparing the order of subjects based on the Patient Satisfaction Survey, it can be stated that the change in order occurred in nine out of a total of eleven cases. The leaders in the first half of the sample show a relatively stable position within the market. Based on the published data (since 2018, the survey no longer states the exact numerical value of the patient satisfaction index), it is possible to monitor the stabilization of the analyzed subjects at the value "average". While in 2018 only nine of the eleven subjects analyzed by us had the value "average", during 2020 all the analyzed subjects within the sample we selected had the evaluation "average". Thus, it can be stated that from the point of view of factors of the traditional world, the subjects of our selected sample managed the adaptation to the turbulent period of the pandemic relatively well. It is also possible, based on the analyzed data, to answer positively the first divided research sub-question. During the period under review, there were changes in the traditional reputation expressed by patient satisfaction surveys in nine out of a total of eleven cases. Regarding the online reputation of the subjects, the situation is considerably more complicated, the following Figure represents a graphical interpretation of the results across the observed period: 


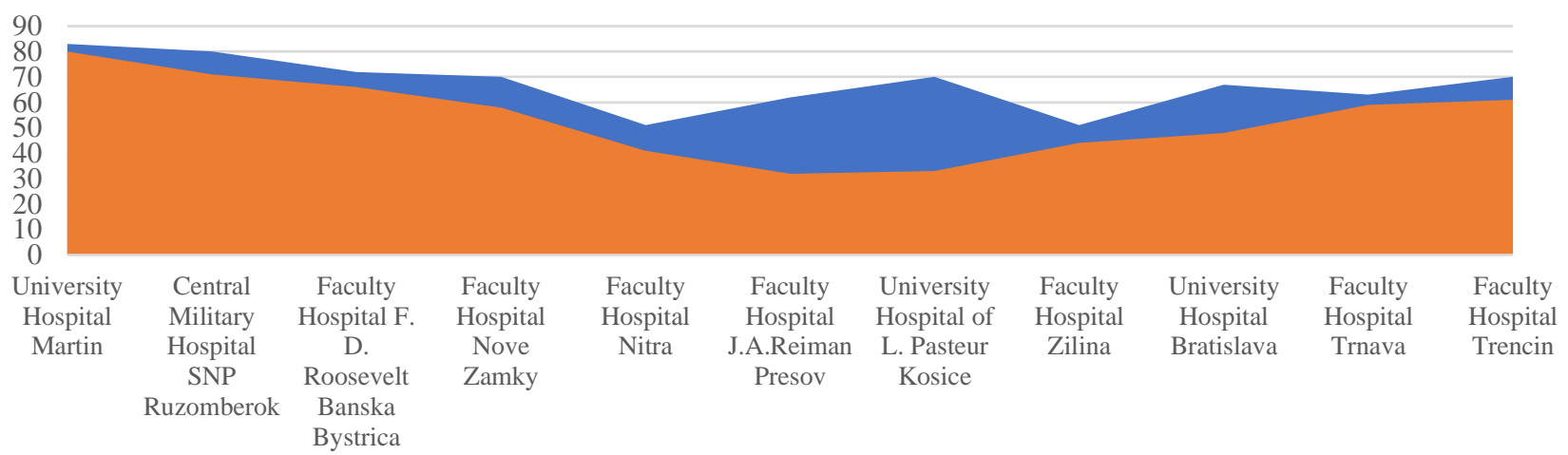

Figure 1. Total Online Reputation score (\%)- 2018 vs. 2021

Source: Author.

In the monitored period, we record a relatively significant decline in online reputation for all entities within the sample we selected. The average value of the decline in the total online reputation is higher than $10 \%$. In light of partial factors, this drop can be justified both by a decrease in the level of positive sentiments in search results (especially in search results in the Google "news" tab) and by a relative decrease in the overall user ratings of entities within the Facebook and Google platforms. Based on the results of the analysis, it is therefore possible to answer the second of the divided research sub-questions. During the pandemic, the subject's level of online reputation changed.

By answering both divided sub-questions, we get to the main research question, in which we asked whether it is possible to identify significant changes in reputation of the analyzed subjects in terms of facts in the period before the outbreak of the pandemic and during the COVID-19 pandemic. Level changes can be identified both in the case of a traditional reputation and in the case of an online reputation. The changes in the case of traditional reputation are less significant, overall, it is possible to state the stabilization of the reputation of the analyzed subjects towards the average. In the case of online reputation, the changes are significant, in all monitored cases it is a decrease in reputation below the reference level measured in the pre-pandemic period.

\section{Conclusion}

Corporate reputation is a relatively complex construct, the management of which requires a wide range of tools and procedures. Even in circumstances that can be described as "normal", it is relatively difficult to optimize all procedures so that the development of this intangible asset can be effectively assessed. The traditional world represented by brickand-mortar tools makes it possible to optimize procedures for effective reputation management relatively predictably. In the presented study, we confirmed this assumption based on a comparison of two reputation rankings developed by a unified Patient Satisfaction Survey methodology, where over time subjects in our sample optimized procedures to stabilize reputation at its average level, despite adverse market factors. In contrast, we recorded a significant decline in the online reputation of entities, wherewith the onset of the pandemic, we observe within the sample a decline in almost all subindicators forming a complex parameter TOR. The unregulated nature of the virtual market, combined with the unpredictability of the pandemic era, has created a set of variables that are relatively difficult to control over time. Resource efficiency requires a thorough knowledge of the issue and current and relevant data. The present study has the ambition to contribute to the expansion of the knowledge base for subsequent comprehensive research into the effects of a pandemic on corporate competitiveness. From the point of view of limitations, it is necessary to point out the relatively high specificity of the market, with certain signs of catching up. Despite this fact, however, it is possible to approach the knowledge generated in the analysis as a general knowledge base, as the specifics of the digital customer largely eliminate market barriers and internationalize findings.

\section{Acknowledgment}

This article is one of the partial outputs of the currently solved research grant VEGA 1/0140/21 "Research on economically important factors of corporate reputation in the context of sustainable industry and low-carbon economy". 


\section{References}

1. L. Hollebeek, K. Macky. Digital Content Marketing's Role in Fostering Consumer Engagement, Trust, and Value: Framework, Fundamental Propositions, and Implications. Journal of Interactive Marketing. 45, 27-41 (2019)

2. O. Iglesias, S. Markovic, M. Bagherzadeh, J. Singh. Co-creation: A Key Link Between Corporate Social Responsibility, Customer Trust, and Customer Loyalty. Journal of Business Ethics. 163(2), 151-166 (2020)

3. J. Soviar, M. Holubčík, J. Vodák, M. Rechtorík, F. Pollák. The Presentation of Automotive Brands in the On-Line Environ-ment-The Perspective of KIA, Peugeot, Toyota and VW in the Slovak Republic. Sustainability. 11, 2132 (2019)

4. J. B. Ziemba, S. Arenberg, H. Reustle, M. E. Allaf, D. Haldeman. Consumers' Association of Hospital Reputation With Healthcare Quality. Journal for Healthcare Quality. 41(4), 251-258 (2019)

5. G. Miotto, C. Del-Castillo-Feito, A. Blanco-González. Reputation and legitimacy: Key factors for Higher Education Institutions' sustained competitive advantage. Journal of Business Research. 122, 342-353 (2020)

6. P. Dorcak, P. Markovic, F. Pollak. Multifactor analysis of online reputation as a tool for enhancing competitiveness of subjects from automotive industry. Ekonomický časopis. 65, 173-186 (2017)

7. F. Pollák. Online reputačný manažment v podmienkach stredoeurópskeho virtuálneho trhu. Prešov: Bookman, (2015)

8. F. Pollák, P. Dorčák, P. Markovič. Corporate Reputation of Family-Owned Businesses: Parent Companies vs. Their Brands. Information. 12(2), 89 (2021)

9. H. Hongwei, L. Harris. The impact of Covid-19 pandemic on corporate social responsibility and marketing philosophy. Journal of Business Research. 116, 176-182 (2020)

10. Y. Y. Jiang, J, Wen. Effects of COVID-19 on hotel marketing and management: a perspective article. International Journal of Contemporary Hospitality Management. 32(8), 2563-2573 (2020)

11. D. Y. Zhang, M. Hu, Q. Ji. Financial markets under the global pandemic of COVID-19. Finance Research Letters. 36, 101528 (2020)

12. F. Pollák, R. Vavrek, J. Váchal, P. Markovič, M. Konečný. Analysis of Digital Customer Communities in terms of their interactions during the first wave of the COVID-19 pandemic. Management \& Marketing. Challenges for the Knowledge Society. 16(2), 134 - 151 (2021)

13. A. C. Schulz, S. Johann. Downsizing and the fragility of corporate reputation: An analysis of the impact of contextual factors. Scandinavian Journal of Management. 34(1), 40-50 (2018)

14. G. Ordonez. Fragility of reputation and clustering of risk-taking. Theoretical Economics. 8(3), 653-700 (2013)

15. VšZP. Prieskum spokojnosti pacientov 2018 [online]. Available at: https://www.vszp.sk/poskytovatelia/indikatorykvality/prieskum-spokojnosti-pacientov-2018/ (2018)

16. VšZP. Prieskum spokojnosti pacientov 2020 [online]. Available at: https://www.vszp.sk/poskytovatelia/indikatorykvality/prieskum-spokojnosti-pacientov-2020/ (2020)

17. R. Štefko, F. Pollák, B. Gavurová. Offline and online approaches to quality perception of Slovak university hospitals. Marketing and Management of Innovations. 4, 107-115 (2018)

18. V. P. Rindova, I. O. Williamson, A. P. Petkova. Reputation as an Intangible Asset: Reflections on Theory and Methods in Two Empirical Studies of Business School Reputations. Journal of Management. 36(3), 610-619 (2010)

19. S. Tadelis. What's in a name? Reputation as a tradeable asset. American Economic Review. 8(3), 548-563 (1999)

20. C. Kobrak. The Concept of Reputation in Business History. Business History Review. 87(4), 763-786 (2013)

21. M. J. Granger, D. L. Schroeder. Integrating the Internet into the business environment. Industrial Management \& Data Systems. 94(8), 37-40 (1994)

22. P. M. Stevens, K. P. Williams, M. C. Smith. Organizational communication and information processes in an Internetenabled environment. Psychology \& Marketing. 17(7), 607-632 (2000)

23. R. T. Rust, W. Rand, M. H. Huang, A. T. Stephen, G. Brooks, T. Chabuk. Real-Time Brand Reputation Tracking Using Social Media. Journal of Marketing. 85(4), 21-43 (2021)

24. F. Pollák, P. Markovič. Size of Business Unit as a Factor Influencing Adoption of Digital Marketing: Empirical Analysis of SMEs Operating in the Central European Market. Administrative Sciences. 11(3), 71 (2021) 
25. G. Appel, L. Grewal, R. Haid. A. T. Stephen. The future of social media in marketing. Journal of the Academy of Marketing Science. 48, 79-95 (2020)

26. F. Pollák, P. Dorčák, P. Markovič, N. Svetozarovová, K. Belovodská. A Comprehensive Analysis of the Online Reputation of Healthcare Providers Operating on the Slovak Market. 37th International Conference on Organizational Science Development: Organization and uncertainty in the digital age. 47 (2018) 